\title{
Test of GNSS Online Service PPP Kinematic Solutions**
}

Abstract: GNSSs are widely used in engineering solutions that demand high accuracy. In areas requiring decimeter precision, Internet online post-processing services are a potential tool for developing GNSS observations. These services have been contributed by a number of organizations, providing users simple, unlimited, and (above all) free access. As a result, online services could be an alternative to complex and expensive commercial programs. Authors analyzed free public online GNSS services for post-processing kinematic 5-second observations in PPP mode with accuracy estimation.

Keywords: GNSS, post-processing, kinematic solutions, online services

* AGH University of Science and Technology, Faculty of Mining Surveying and Environmental Engineering, Department of Integrated Geodesy and Cartography, Krakow, Poland

** This paper is the research carried out within statutory research grant no. 11.11.150.444 and 15.11.150.397 in the Department of Integrated Geodesy and Cartography, AGH University of Science and Technology, Krakow, Poland 


\section{Intro}

Precise Point Positioning (PPP) is a relatively new technique for precise satellite positioning that has only been in use for a few years. As an absolute positioning tool, PPP is a very expedient technique due to its independence from reference station(s) and the errors connected with it/them. PPP provides a relatively high accuracy; however, it requires use of a dual-frequency receiver and high-precision products. PPP observations equations on the $L_{i}$ frequency for code and phase respectively are defined as [3]:

$$
\begin{gathered}
P_{i}^{g}=\rho_{g}+c d t^{g}-c d T^{g}+d_{\text {org }}^{g}+d_{\text {trop }}^{g}+d_{\left(\text {ion } / P_{i}\right)}^{g}+d_{\left(\text {multi } / P_{i}\right)}^{g}+\varepsilon_{\left(P_{i}\right)}^{g} \\
\Phi_{i}^{g}=\rho_{g}+c d t^{g}-c d T^{g}+d_{\text {orb }}^{g}+d_{\text {trop }}^{g}-d_{\left(\text {ion } / \Phi_{i}\right)}^{g}+d_{\left(\text {multi } / \Phi_{i}\right)}^{g}-\lambda_{i}^{g} N_{i}^{g}+\varepsilon_{\left(?_{i}\right)}^{g}
\end{gathered}
$$

where:

$$
\begin{aligned}
& P_{i} \text { - the measured pseudorange on } L_{i}[\mathrm{~m}] \text {, } \\
& \Phi_{i} \text { - the measured carrier phase on } L_{i}[\mathrm{~m}] \text {, } \\
& \rho \text { - the true geometric range }[\mathrm{m}] \text {, } \\
& c \text { - the speed of light }[\mathrm{m} / \mathrm{s}] \text {, } \\
& d t \text { - the receiver clock error [s], } \\
& d T \text { - the satellite clock error [s], } \\
& \lambda_{i} \text { - the wavelength on } L_{i}[\mathrm{~m} / \text { cycle], } \\
& N_{i} \text { - the integer phase ambiguity on } L_{i}[\mathrm{~m} / \text { cycle], } \\
& \varepsilon \text { - the measurement noise [m], } \\
& d_{\text {orb }} \text { - the satellite orbit error [m], } \\
& d_{\text {trop }} \text { - the tropospheric delay [m], } \\
& d_{\text {ion } / L_{i}} \text { - the ionospheric delay on } L_{i}[\mathrm{~m}] \text {, } \\
& d_{\text {multi/Li }} \text { - the multipath effect in the measured pseudorange on } L_{i}[\mathrm{~m}] \text {, } \\
& d_{\text {multi } / \Phi_{i}} \text { - the multipath effect in the measured carrier phase on } L_{i}[\mathrm{~m}] \text {. }
\end{aligned}
$$

The parameters calculated in Equations (1) and (2) depend on orbit errors, clocks and satellite receiver errors, tropospheric and ionospheric delay, and integer ambiguity estimation. The use of products such as precise orbit and satellite clock files minimize satellite orbits errors and clock errors. A linear combination of code and phase (ionosphere-free) also allows for the elimination of ionosphere influence. To that end, unknown are the troposphere delay, receiver clock error, and the initial value of the integer phase ambiguity. The PPP technique is mainly used in advanced tools for GNSS (Global Navigation Satellite System) post-processing (like e.g., Bernese GNSS Software or GAMIT-GLOBK), but it is also being used increasingly by online Internet services users.

Currently, kinematic solutions are most-frequently identified with the very popular RTK (Real Time Kinematic) technique. In RTK mode, a user's position is determined by the use of one or more GNSS reference stations in real time. However, 
in this paper, the user's position was calculated in kinematic mode on the basis of "raw" observation data in post-processing. As a result, a set of coordinates was calculated for each epoch in the observation file. Such kinematic solutions apply primarily in monitoring short-term coordinate changes caused by natural or anthropogenic phenomena. Analysis of kinematics can be used (for example) in the study of vibrations in the Earth's crust [7] or in issues relating to control of the state of engineering structures [11]. The main advantage in relation to the RTK technique is the possibility of various ways and options of processing observation data depending on the purpose of the measurement.

In addition to its high price, commercial software used for the analysis of GNSS observations also requires additional expertise about the global navigation satellite system structure and its observation processing. Therefore, this type of software is mainly used by a narrow range of GNSS professionals. Online GNSS services provide free, unlimited, and almost-immediate solutions. Their interfaces are also very intuitive and friendly, even for inexperienced users. Therefore, online services can be an alternative to commercial solutions, especially in applications where high accuracy (centimeters) and precision are not required.

Studies on the accuracy of online GNSS services mainly concerned long, 24-hour observations with a long sampling rate. As an example, Ocalan et al. [9] conducted an analysis of solutions from several reference stations based on 24-hour observations with 30-second intervals. By contrast, Ghoddousi-Fard and Dare [4] analyzed the accuracy of one- and two-hour static observations by a couple of online services. However, in the work [2], rapid static models were used for various lengths of observing sessions between eight minutes to almost two hours.

Each of the above works has shown that the accuracy of the static observation obtained by GNSS online services can (depending on the length of the observation session) achieve an accuracy of $<5 \mathrm{~cm}$ in the case of flat components as well as $<10 \mathrm{~cm}$ for height. However, all of these types of work are related to the development of solutions in static absolute or differential mode. But there is no work on describing kinematic solution accuracy analysis in the post-processing mode made through online GNSS services.

\section{Characteristic of Analyzed Services}

Currently, there are several GNSS online services that provide free access with a global reach (Tab. 1).

The development of GNSS measurements with the use of each service listed in Table 1 requires a RINEX observation file with a specified minimum number of observations and sampling interval. Files can be sent via website, e-mail, or by ftp server. The user must also choose the mode of processing: static/kinematic and absolute/differential. Online services are based mostly on high-precision IGS products (precise orbit and clocks). 
Table 1. GNSS online services

\begin{tabular}{||l|l||}
\hline \multicolumn{1}{|c|}{ Service } & \multicolumn{1}{c|}{ Institution/Organisation } \\
\hline APPS & Jet Propulsion Laboratory, California Institute of Technology, USA \\
\hline AUSPOS & Geoscience Australia \\
\hline CenterPoint RTX & Trimble Navigation \\
\hline CSRS-PPP & Canadian Spatial Reference System, Natural Resources, Canada \\
\hline GAPS & University of New Brunswick. New Brunswick, Canada \\
\hline Opus & National Geodetic Survey, USA \\
\hline MagicGNSS & GMV Aerospace and Defense, Spain \\
\hline SCOUT & University of California, San Diego, USA \\
\hline
\end{tabular}

Among the services listed in Table 1, we used the ones with available kinematic PPP mode for further analysis. Therefore, two of them were eliminated - AUSPOS and SCOUT $[1,12]$ - due to differential positioning only. Among other services, we excluded the ones with only static solutions - CenterPoint RTX and OPUS [14, 10]. Finally, for further analyses, we accepted four of them: APPS, CSRS, GAPS, and magicGNSS.

The Automatic Precise Positioning Service of the Global Differential GPS System (APPS) was maintained by one of NASA's research centers - the Jet Propulsion Laboratory. This service requires RINEX 2.0 or later. Files can be transmitted by e-mail, ftp server or loaded from a user's drive. The calculated coordinates are in an ITRF2008 frame. APPS provides four types of PPP solutions: static, kinematic, Near Real Time (NRT), and Most Accurate (MA). Method NRT provides the fastest solution on the basis of the currently available files of GPS orbits and clocks. The MA method provides the most-accurate solutions based final clocks and orbits [13]. Solutions in the form of a text file are sent to the user's e-mail account.

The Canadian Spatial Reference System PPP (CSRS) service was established by Natural Resources Canada. CSRS requires free user registration, and the observations are loaded from a hard drive. CSRS enables users to process data in the static and kinematic PPP modes. The results can be projected in NAD83 or current ITRF realization frames. Solutions in the form of a text file are sent to the user's e-mail account [8].

GNSS Analysis and Positioning Software Description (GAPS) was created and is maintained by researchers at the University of Brunswick. Unlike other analyzed online services, GAPS contains the largest range of process options. GAPS allows users to access (e.g.) GPS, Galileo and Beidou observations, the type of orbit and clock products, the code and phase observations, or even load an antenna calibration model. Results are can be shown in either ETRF or ITRF realization and sent via e-mail to the user [5]. 
The magicGNSS service provides solutions for its registered users via its website or for unregistered users by an appropriate e-mail form. magicGNSS provides static and kinematic PPP processing, using GPS, GLONASS, and Galileo observations. magicGNSS is the only analyzed service that allows users to transfer multiple files at the same time. However, in the case of sending two RINEX files from the same station, it also prepares a comparative summary of the differences between coordinates [6].

\section{Results and Discussion}

In this paper, there were analyzed 12-hour observation files with 5-second intervals on the KRAW station belonging to EPN. Observations were registered on the $17^{\text {th }}$ and $24^{\text {th }}$ of September, 2016 (respectively, the $261^{\text {st }}$ and $268^{\text {th }}$ day of the year DOY). Under consideration were GPS-only observations with IGS Final orbits and clock files. EPN high-rate observations are available as single 15-minute observations files. The authors' combined 48 consecutive periods, resulting in two 12-hour observation files for each of the analyzed days. Services provide results in various frames, all of which were transformed into ITRF08 at the observation epoch. Subsequently, there were calculated differences between the result coordinates and the coordinates from the final daily EPN solution at the observation epoch. Finally, the differences above were transformed into topocentric NEU coordinates. The time series for each North, East, and Up component are shown in Figures 1, 2, and 3.
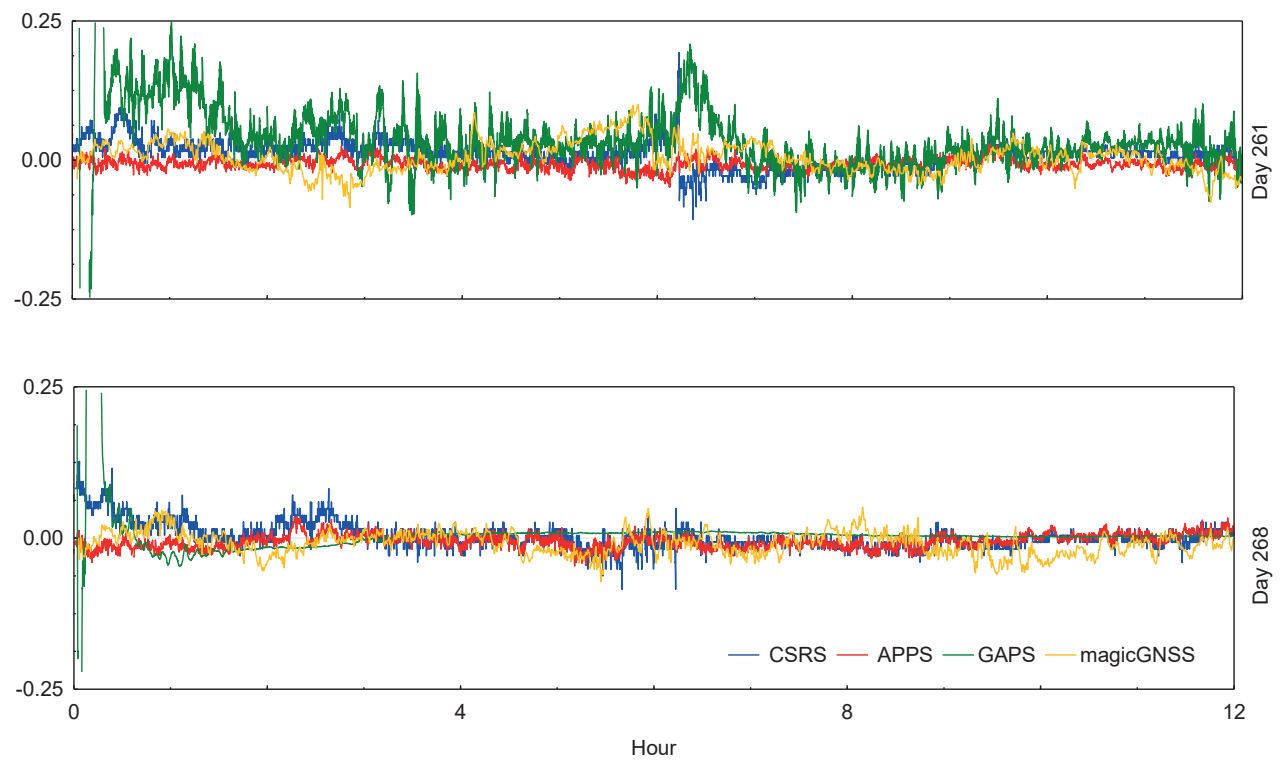

Fig. 1. Time series of North component [m] 
Figure 1 shows the time series of the North component. The highest accuracy was provided by APPS. For the two analyzed days, the deviation of the North component was the smallest from all of the analyzed services. Similar accuracy levels were achieved by CSRS and magicGNSS. For both days, the least-accurate service was GAPS; the solutions showed significant random deviations, some of which exceeded $25 \mathrm{~cm}$. In addition, very clearly visible are differences between the $261^{\text {st }}$ and $268^{\text {th }}$ DOY for GAPS. For the rest of the results, maximum deviation of the North component did not exceed $10 \mathrm{~cm}$.

Figure 2 shows the time series of the East component. The same as for the North component, the most-accurate service is APPS. The CSRS and magicGNSS results were at a similar accuracy level. The least-precise East component was determined by the GAPS service. Coordinate deviations of the APPS and magicGNSS solutions did not exceed $5 \mathrm{~cm}$, and in the case of the GAPS service $-10 \mathrm{~cm}$. Meanwhile, the maximum deviations provided by GAPS often exceeded even $25 \mathrm{~cm}$. Comparing the various solutions on 261 and 268, it should be noted clearly repeatable solutions for all services instead of GAPS's. It especially seen in very low precision for GAPS on 261 DOY.

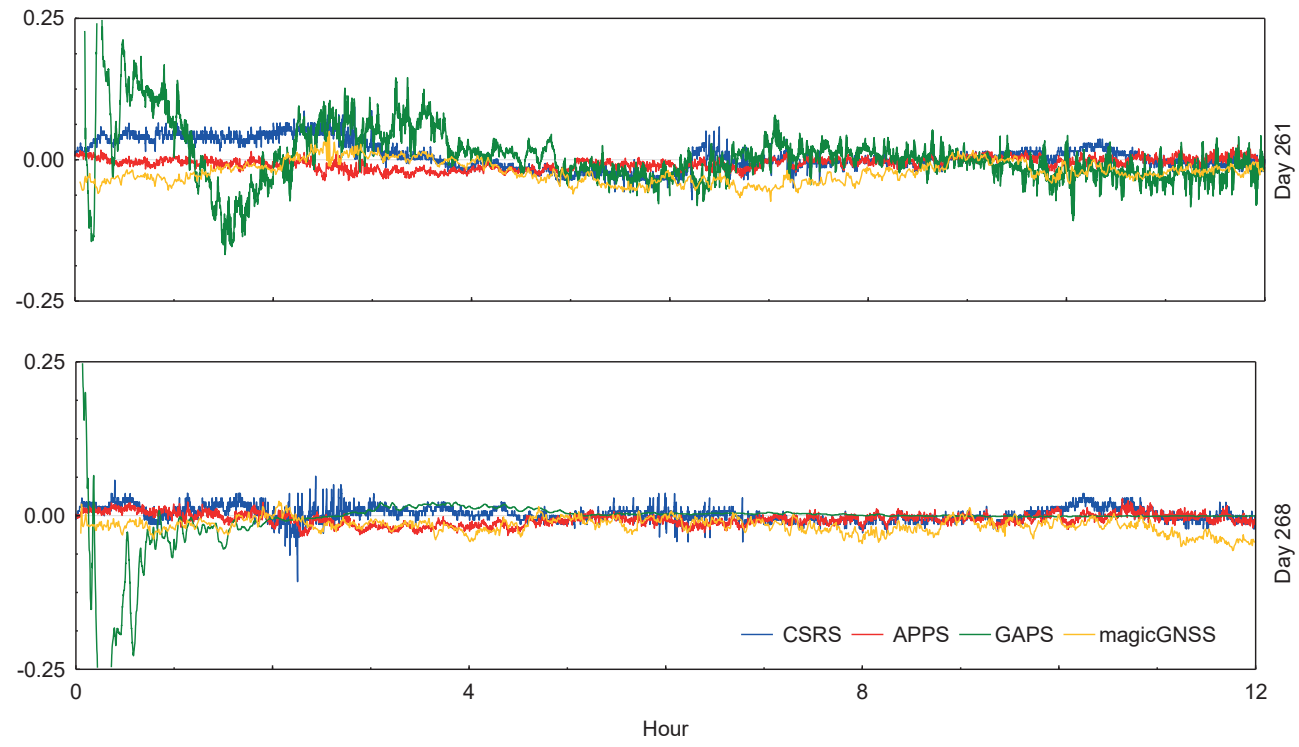

Fig. 2. Time series of East component [m]

Conclusions of the Up component solutions are similar to the North and East components. In addition, very large errors can clearly be seen at the beginning of processing for some services. This is particularly evident for the first two hours; it is the result of incorrectly processed initial values of phase ambiguity. For the $268^{\text {th }}$ DOY starting at approximately the second hour, all coordinates are at the same accuracy level in principle. 

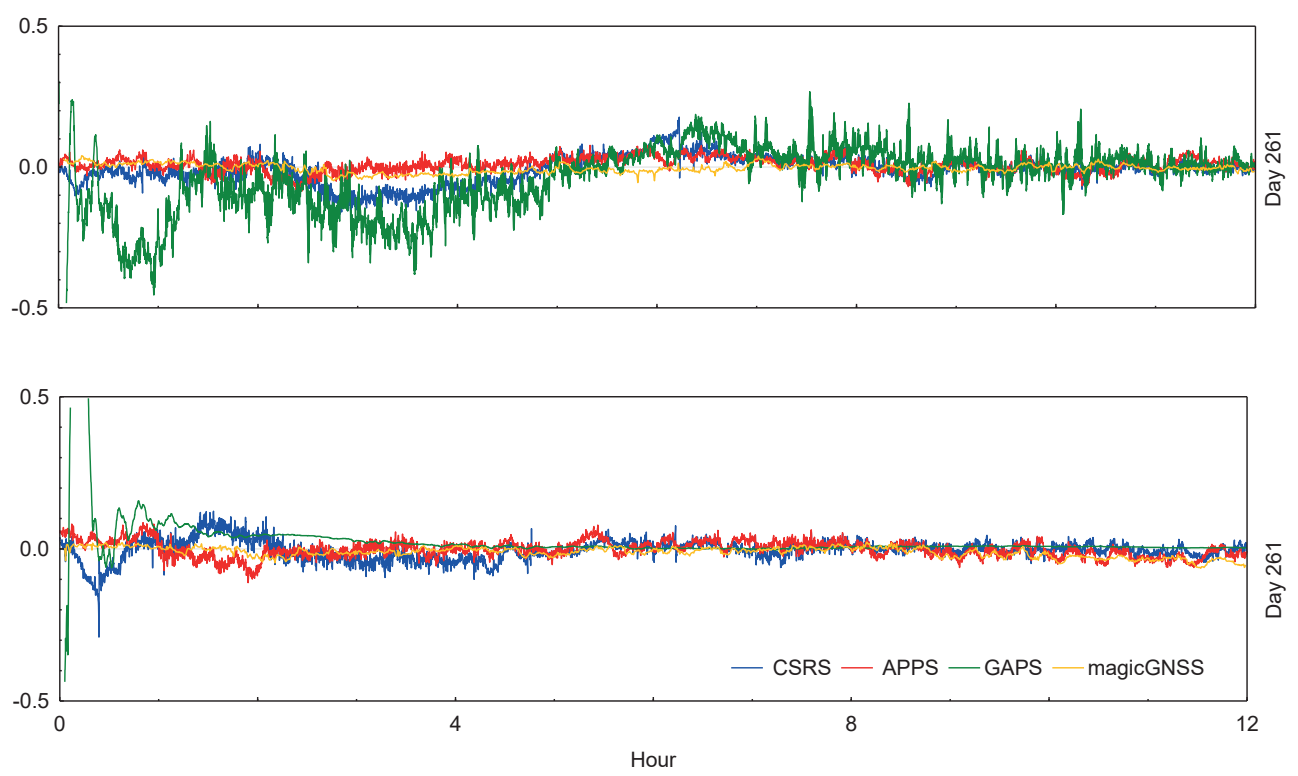

Fig. 3. Time series of Up component [m]

Table 2 shows average absolute deviations and standard deviations for the analyzed days. For each case, the most-accurate turned out to be the APPS service. The $\mathrm{NE}$ components were determined with an average error of $1 \mathrm{~cm}$, and the Up component was around a 2-cm error. Very-similar solutions were provided by the CSRS and magicGNSS services. The standard deviation of the North component did not exceed $2 \mathrm{~cm}$ and $2.2 \mathrm{~cm}$, respectively; for the East component $-2 \mathrm{~cm}$ and $2.4 \mathrm{~cm}$, respectively; and $3.6 \mathrm{~cm}$ and $1.5 \mathrm{~cm}$, respectively, for both CSRS and magicGNSS. The least-accurate solutions were provided by the GAPS service - especially for the $261^{\text {st }}$ DOY. Medium deviation of the North and Up components exceeded $14 \mathrm{~cm}$, with an average error of more than $6 \mathrm{~cm}$.

Table 2. Mean absolute coordinate deviations and standard deviations

\begin{tabular}{|c|c|c|c|c|c|c|c||}
\hline \hline Day & Service & $N[\mathrm{~cm}]$ & $\sigma_{N}[\mathrm{~cm}]$ & $E[\mathrm{~cm}]$ & $\sigma_{E}[\mathrm{~cm}]$ & $U[\mathrm{~cm}]$ & $\sigma_{u}[\mathrm{~cm}]$ \\
\hline \hline \multirow{4}{*}{261} & CSRS & 1.6 & 2.0 & 1.6 & 2.0 & 3.3 & 3.6 \\
\cline { 2 - 8 } & APPS & 0.7 & 1.0 & 0.7 & 0.9 & 1.6 & 2.2 \\
\cline { 2 - 8 } & GAPS & 13.1 & 6.2 & 7.8 & 4.3 & 13.3 & 9.5 \\
\cline { 2 - 8 } & magicGNSS & 1.8 & 2.2 & 1.5 & 2.4 & 0.9 & 1.3 \\
\hline \multirow{3}{*}{268} & CSRS & 1.5 & 1.5 & 0.8 & 0.9 & 2.3 & 2.4 \\
\cline { 2 - 9 } & APPS & 0.7 & 1.0 & 0.7 & 0.9 & 1.7 & 2.1 \\
\cline { 2 - 8 } & GAPS & 9.4 & 2.1 & 7.1 & 1.9 & 13.0 & 3.8 \\
\cline { 2 - 8 } & magicGNSS & 1.3 & 1.7 & 1.1 & 1.7 & 1.3 & 1.5 \\
\hline
\end{tabular}


Analyzing solutions between the $261^{\text {st }}$ and $268^{\text {th }}$ DOY for the APPS, CSRS, and magicGNSS services solutions did not differ fundamentally from each other - the average and standard deviation are similar. However, in the case of GAPS, each component on the $261^{\text {st }}$ DOY was determined as half as accurate as compared to the $268^{\text {th }}$ DOY. Each GAPS coordinate component for the $261^{\text {st }}$ DOY was determined with standard deviations of $6.2 \mathrm{~cm}, 4.3 \mathrm{~cm}$, and $9.5 \mathrm{~cm}$, respectively, as compared to the $268^{\text {th }}$ DOY; these were $2.1 \mathrm{~cm}, 1.9 \mathrm{~cm}$, and $3.8 \mathrm{~cm}$, respectively.

\section{Summary}

This article compares 5-second kinematic solutions in the PPP mode using online GNSS services. Our results show significant differences between the services we tested. In the case of APPS, the smallest discrepancy in the solutions for the analyzed days was observed. CSRS and magicGNSS show similar accuracy between individual days and between each other.

An analysis of the comprehensive results is difficult due to the lack of detailed descriptions of the processing algorithms. The APPS service based on Gipsy Oasis v. 6.3 software, and GAPS is based on GAPS V6.0.0 r587 software. Meanwhile, there is no detailed information about used software in CSRS and magicGNSS. In addition, an analysis of the long-time series PPP mode is difficult due to the technical limitations of the file sizes on the online services. The limitations above lead us to the conclusion that scientific research based on the PPP technique is needed to develop or use alternative software.

\section{References}

[1] AUSPOS - Online GPS Processing Service - Geoscience Australia, [on-line:] http://www.ga.gov.au/scientific-topics/positioning-navigation/geodesy/ auspos [access: 25.03.2016].

[2] Berber M., Ustun A., Yetkin M.: Rapid static GNSS data processing using online services. Journal of Geodetic Science, vol. 4(1), 2014, pp. 123-129.

[3] Cai C., Gao Y.: Precise Point Positioning Using Combined GPS and GLONASS Observations. Journal of Global Positioning Systems, vol. 6(1), 2007, pp. 13-22.

[4] Ghoddousi-Fard R., Dare P.: Online GPS processing services: An initial study. GPS Solutions, vol. 10(1), 2006, pp. 12-20.

[5] GNSS Analysis and Positioning Software, [on-line:] http://gaps.gge.unb.ca [access: 25.03.2016].

[6] MagicGNSS - Quality Data, Algorithms and Products for the GNSS User Community, [on-line:] https://magicgnss.gmv.com [access: 25.03.2016]. 
[7] Moschas F., Avallone A., Moschonas N., Saltogianni V., Stiros S.: Assessment of accuracy of PPP for very-hight-frequency dynamic, satellite positioning and earthquake modeling. [in:] EGU General Assembly 2012, 22-27 April, 2012 in Vienna, Austria, 2012, pp. 42-52.

[8] Natural Resources Canada Precise Point Positioning, [on-line:] http://webapp.geod.nrcan.gc.ca/geod/tools-outils/ppp.php [access: 25.03.2016].

[9] Ocalan T., Erdogan B., Tunalioglu N.: Analysis of web-based online services for GPS relative and precise point positioning techniques. Boletim de Ciencias Geodésicas, vol. 19(2), 2013, pp. 191-207.

[10] OPUS - National Geodetic Survey - NOAA, [on-line:] http://ngs.noaa.gov/ OPUS [access: 31.03 .2016$]$.

[11] Roberts G., Dodson A., Brown C.: Monitoring the height deflections of the Humber Bridge by GPS, GLONASS, and finite element modeling. [in:] Conference Geodesy Beyond 2000 - The Challenges of the First Decade, International Association of Geodesy Symposia (IAG SYMPOSIA), vol. 121, 2000, pp. 355-360.

[12] Scripps Orbit and Permanent Array Center, [on-line:] http://sopac.ucsd.edu/ scout.shtml [access: 31.03.2016].

[13] The Automatic Precise Positioning Service of the Global Differential GPS System, [on-line:] http://apps.gdgps.net [access: 31.03.2016].

[14] Trimble Centerpoint ${ }^{\mathrm{TM}}$ RTX ${ }^{\mathrm{TM}}$ Post-Processing Service, [on-line:] http:// www.trimblertx.com [access: 31.03.2016].

\section{Test rozwiązań kinematycznych PPP internetowych serwisów GNSS}

Streszczenie: Systemy GNSS znajdują obecnie szerokie zastosowanie w rozwiązaniach inżynierskich wykorzystujących techniki geodezyjne. W dziedzinach wymagających dokładności decymetrowych bądź centymetrowych potencjalnym narzędziem do opracowania pomiarów satelitarnych mogą być internetowe serwisy post-processingu GNSS. Rozwiązania tego typu udostępniane są przez szereg organizacji, zapewniając użytkownikom prosty, nielimitowany i przede wszystkim bezpłatny dostęp do oferowanych usług obliczeniowych. Serwisy te stanowią tym samym alternatywne rozwiązanie względem skomplikowanych i kosztownych programów komercyjnych. Autorzy przeanalizowali ogólnodostępne, darmowe serwisy online do post-processingu obserwacji GNSS umożliwiające 5-sekundowe rozwiązania kinematyczne w trybie PPP oraz przedstawili oszacowanie dokładności tego typu opracowań.

Słowa

kluczowe: GNSS, post-processing, rozwiązania kinematyczne, internetowe serwisy GNSS 